\title{
0 estudio do caso como metodoloxía activa no Mestrado en Eficiencia e Aproveitamento Enerxéticos
}

\author{
De Llano Paz, Fernando'; Calvo-Silvosa, Anxo; Iglesias Gómez, Guillermo; Martínez \\ Fernández, Paulino'; Bajo Buenestado, Raúl ${ }^{2}$ \\ ${ }^{1}$ Universidade da Coruña, Facultade de Economía e Empresa \\ ${ }^{2}$ Universidad de Navarra, Facultad de Ciencias Económicas y Empresariales \\ GID-UDC en Operacións Financeiras, Economía Enerxética e Economía Circular
}

\section{RESUMO}

Dentro do Mestrado en Eficiencia e Aproveitamento Enerxético da UDC que se desenvolve en Ferrol, impártese a materia de "Política Enerxética e Análise de Investimentos". A detección por parte do profesorado da existencia de realidades académicas previas moi diversas entre 0 alumnado, permitiu converter este elemento nun eixo dinamizador do proceso de ensinanza-aprendizaxe. Para vehicular esta realidade óptase por empregar a metodoloxía activa do estudo do caso. Planifícase a materia para que cada sesión de aula teña un estudo do caso a partir do cal desenvolver os diferentes contidos da mesma. 0 caso é proposto por un/ha experto/a diferente das distintas empresas do sector, que teñen relación co Mestrado a partir das prácticas. 0 contexto de ensinanza-aprendizaxe gaña en motivación. 0 profesorado pasa a ser punto de información ao que acudir, deixando de ser o punto de atención principal. Como contrapartida para o profesorado os tempos de preparación da materia son elevados. Esforzo que se ve recompensado con creces ao ver os resultados: unha experiencia formativa moi enriquecedora con base na relación alumnado-alumnado, quen grazas á súa formación previa, ven potenciada a asimilación de conceptos e a adquisición das competencias propias da materia.

PALABRAS CLAVE: Metodoloxías activas; Método do caso; Mestrado; Expertas/os. 


\section{CITA RECOMENDADA:}

De Llano Paz, Fernando; Calvo-Silvosa, Anxo; Iglesias Gómez, Guillermo; Martínez Fernández, Paulino; Bajo Buenestado, Raúl (2020): 0 estudio do caso como metodoloxía activa no Mestrado en Eficiencia e Aproveitamento Enerxéticos. En De la Torre Fernández, E. (ed.) (2020). Contextos universitarios transformadores: Boas prácticas no marco dos GID. IV Xornadas de Innovación Docente. Cufie. Universidade da Coruña. A Coruña (págs. 149-162).

DOI capítulo: https://doi.org/10.17979/spudc.9788497497756.149

DOl libro: https://doi.org/10.17979/spudc. 9788497497756

\section{ABSTRACT}

Within the UDC's Master's Degree in Energy Efficiency and Use, which is being held in Ferrol, the subject of "Energy Policy and Investment Analysis" is taught. The detection by the teaching staff of the existence of very diverse previous academic realities among the students, allowed to turn this element into a dynamic axis of the teaching-learning process. In order to convey this reality, the active methodology of the case study was used. The subject is planned so that each classroom session has a case study from which to develop the different contents. The case is proposed by a different expert from the different companies in the sector, which are related to the Master from the practices. The teaching-learning context gains in motivation. The teaching staff becomes a point of information to which to go, no longer the main focus of attention. In return, the teachers have to spend a lot of time preparing for the subject. This effort is more than rewarded when the results are seen: a very enriching training experience based on the relationship between students and pupils, who, thanks to their previous training, see the assimilation of concepts and the acquisition of the skills of the subject enhanced.

KEY WORDS: Active methodologies; Case method; Master's degree; Experts. 


\section{INTRODUCIÓN}

A materia de "Política Enerxética e Análise de Investimentos" impártese no Mestrado en Eficiencia e Aproveitamento Enerxético da UDC, que se desenvolve na Escola Universitaria Politécnica de Ferrol (EUP, en diante). Trátase dunha materia que inclúe profesores das áreas de "Economía Financeira e Contabilidade" e de "Economía Aplicada", e que á súa vez forman parte do GID da UDC en Operacións Financeiras, Economía Enerxética e Economía Circular.

Nos últimos anos obsérvase a existencia de realidades académicas e laborais previas moi diversas entre 0 alumnado que realiza o Mestrado. Deste xeito mestúranse na aula alumnas/os que continúan estudos despois de facer un grao da rama de enxeñaría ou arquitectura con outras/os que proveñen da rama de ciencias. E á súa vez hai tanto alumnado que non tivo experiencia laboral previa con outro que leva varios anos traballando e realiza 0 Mestrado como ponte para a busca dun posto laboral diferente ao actual. É a partir deste contexto académico-laboral diverso cando o profesorado da materia propuxemos converter este elemento nun eixo dinamizador do proceso de ensinanza-aprendizaxe (Figura 1).

Deste xeito o papel principal do proceso pasa do profesorado ao alumnado (Riesco, 2008). A formación previa do alumnado é a base de traballo coa que conseguir a asimilación dos novos conceptos propostos na materia. Facilitase así unha contorna de aprendizaxe positiva que potencia a adquisición das competencias propias da materia.

Para vehicular esta realidade óptase por empregar a metodoloxía activa do estudo do caso. Planifícase a materia para que cada sesión de aula teña un estudo do caso a partir do cal desenvolver os diferentes contidos da mesma.

0 profesorado convértese nun equipo asesor, renunciando ao papel principal. Con este cambio metodolóxico increméntanse os tempos de preparación da materia por parte do profesorado. Aínda así, este esforzo vese recompensado en forma de motivación extra no alumnado, que enriquece a súa experiencia formativa a partir da relación entre iguais: alumnado-alumnado. 
Mestrado en Eficiencia e Aproveitamento Enerxético da UDC en Ferrol Materia: "Política Enerxética e Análise de Investimentos"

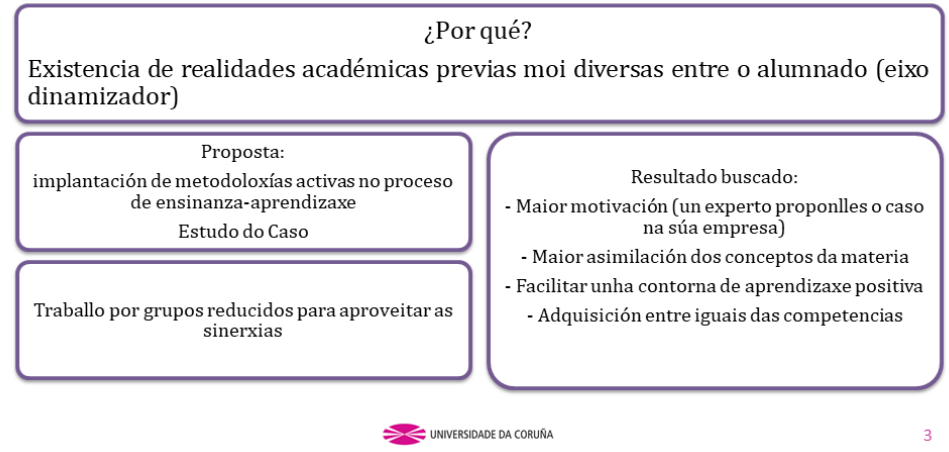

Figura 1. Motivación da proposta

0 traballo desenvólvese nos seguintes apartados: No seguinte punto descríbese a base teórica da experiencia, no terceiro punto defínese a proposta metodolóxica e no cuarto apartado achégase a conclusión principal.

\section{DESCRICIÓN DA EXPERIENCIA. BASE TEÓRICA}

Segundo o exposto, a proposta metodolóxica pivota en dous elementos chave: a relación alumnado-alumnado e o estudo do caso como ferramenta educativa. A continuación desenvolveranse ambos, e así describirase a experiencia.

\section{1. A relación alumnado-alumnado}

0 Espazo Europeo de Educación Superior basea a súa proposta no alumnado, como eixo fundamental do proceso de ensinanza-aprendizaxe. Preténdese así que a formación que reciba na Universidade sirva para desenvolver aquelas competencias que a/o leven a conseguir emprego de calidade, a facilitar a súa mobilidade laboral e a exercitar a capacidade de aprender de xeito continuado coa que poder xestionar os posibles cambios laborais e profesionais que estas actividades lle esixan (Robledo et al. 2015; Riesco 2008). 
Neste contexto xorde 0 novo paradigma do papel dos axentes do proceso ensinanzaaprendizaxe. Mentres que os docentes pasan de ser "transmisores de coñecemento" (papel discursivo) a ser "guías ou acompañantes" (papel reflexivo), o alumnado pasa a caracterizarse por presentar unha maior implicación e compromiso, unha maior autonomía e por desenvolverse nunha contorna de aprendizaxe baseada na "negociación persoal" entre iguais (Bará e Domingo, 2005; Cano, 2009; Fernández e De-Llano, 2013).

Deste xeito o proceso deixa de ter á/ao docente como axente principal, para converterse nunha vivencia compartida entre iguais, onde cada axente en formación achega a súa experiencia e coñecementos previos para solucionar os problemas aos que se enfronta no propio proceso de asimilación de novos conceptos e desenvolvemento das competencias.

Trátase, por tanto, dunha interacción entre iguais. Segundo afirman Gutierrez e Castro (2018), a transformación educativa parte da interacción baseada na linguaxe, no diálogo igualitario e a imitación. Deste xeito, segundo estes autores, pásase dunha visión tradicional de aprendizaxe caracterizada por unha recepción pasiva de coñecementos a outra na que a "activación" e a "motivación" do alumnado facilita comportamentos de axuda mutua e diálogo reflexivo.

Segundo Alonso (2008) isto encaixaría dentro dos roles a asumir polo alumnado no EEES. Algúns dos cambios que se deben de producir no alumnado son os seguintes:

- Pasar de asimilar contidos transmitidos pola/o docente a ser xestor da súa propia aprendizaxe mediante a busca, selección e actualización da información.

- Aprender a través da reconstrución social do coñecemento. Para isto precisa compartir aquilo que xa coñece e domina, compartilo cos iguais, expoñer e saber xustificar as súas ideas e opinións e replicar con argumentos os esquemas e afirmacións propias e alleas.

- Adquirir tanto o coñecementos da materia como as súas competencias. Para iso a súa actitude cara a aprendizaxe debe ser activa, cooperativa, autónoma, reflexiva e responsable. 
- Ser quen de adaptar o aprendido a novas situacións ou esquemas, e non tanto repetir ou memorizar. 0 alumnado debe analizar, sintetizar, criticar, comparar, etc.

A experiencia que se propón no Mestrado inclúe alumnado con distintas capacidades e "mochilas" formativas e vitais moi diversas. É precisamente esta diversidade, que é aceptada dentro do grupo de aula, a que potencia o proceso de ensinanza-aprendizaxe. Isto é así porque que é aceptada como unha "fortaleza e oportunidade para o enriquecemento mutuo" (Gutierrez e Castro, 2018).

\section{2. 0 estudo do caso como metodoloxía activa}

A proposta metodolóxica que se propón baséase na utilización do estudo do caso como ferramenta central.

Esta técnica fundaméntase nunha análise intensiva sobre un tema ou feito con base real. Ten como finalidade a interpretación ou coñecemento do caso proposto, así como a súa posible resolución a partir dun proceso que englobaría a xeración e contratación de hipóteses, a análise, xestión e interpretación dos datos e, ás veces, 0 adestramento nos distintos procedementos de obtención de solucións (de Miguel et al., 2005). Bozu (2008: 285), sinala que a finalidade desta técnica no é outra que "comprender en profundidade unha realidade singular: individuo, grupo, programa, comunidade, etc.".

Entre os obxectivos desta metodoloxía atoparíanse os seguintes (Bozu, 2008):

- Describir e analizar situacións únicas.

- Xerar hipóteses para posteriormente contrastalas coas de outros estudos rigorosos.

- Adquirir coñecementos.

- Diagnosticar unha situación, para orientar, levar a cabo un asesoramento, etc.

Cada caso proposto é definido no momento inicial da aula nas liñas principais, e posteriormente é desenvolvido polos grupos pequenos de aula formados ao efecto. 0 que conduce a unha aprendizaxe activa é precisamente este proceso de comprensión e interpretación do caso, así como a análise dos diferentes puntos de vista amosados polos 
membros do grupo no proceso de toma de decisións, e a posta en común final que leva a propoñer unha conclusión ou unha decisión ao caso. É dicir, o feito de ter que propoñer finalmente unha solución ao caso proposto conduce a que 0 alumnado integre os distintos elementos nun proceso reflexivo e, a aprendizaxe sexa, polo tanto, significativa (de Miguel et al., 2005).

Entre as principais vantaxes que favorece esta metodoloxía estarían o adestramento en análises de situacións ou temas concretos, así como na resolución de problemas realistas; a experimentación significativa e de práctica profesional; a motivación pola aprendizaxe relacionada cos "contextos de traballo en grupo" relacionados co desenvolvemento profesional e 0 traballo das competencias comunicativas, xestión de grupos e as propias de resolución de conflitos (de Miguel et al., 2005).

Pola súa banda, os principais inconvenientes estarían relacionados coa limitación das propostas reais enunciadas debido a unha elevada complexidade, ou a solucións non realistas que non resolven o problema proposto co caso e as posibles dificultades relacionadas coa xestión interna dos grupos (roles, conflitos, exceso de participantes, etc.).

Dentro da clasificación que fai Bozu (2008), os estudos propostos nesta materia do Mestrado serían do tipo descriptivo e interpretativo, mais non avaliativo. Deste xeito, o estudo do caso descriptivo, segundo a autora, serían aqueles que buscan xerar como produto final un informe completo da situación ou realidade proposta sen necesidade dunha fundamentación teórica. Búscase achegar información básica sobre unha serie de hipóteses previas. A análise chega a ser exhaustiva e precisa, e se basea tanto nos datos achegados polo relator que presenta a situación (docente ou profesional dunha empresa), como polos que poden coñecerse a través da busca por internet. Por outra banda, o estudo de caso interpretativo ou explicativo pretende interpretar ou teorizar sobre unha realidade ou situación proposta. Búscase establecer conexións entre os acontecementos para así poder clarificar supostos de partida. Fundaméntase así en categorías de tipo conceptual ou teórico coas que poder ilustrar ou debater sobre a temática desexada. Ben é certo que se en ambos casos o produto final 
consiste ademais en valorar ou enxuizar o caso, o estudo do caso incluirá ademais a característica de avaliativo.

\subsubsection{O ROL DO PROFESORADO NA METODOLOXÍA DO ESTUDO DO CASO}

0 papel activo do profesorado céntrase sobre todo na fase previa á actividade na aula. Así 0/a docente debe establecer os obxectivos e as competencias a desenvolver na aula, elaborar 0 enunciado con todos os recursos que se queren traballar, as preguntas chave, posibles elementos de debate, dinámicas internas e tarefas a levar cabo polos/as estudantes. Dunha boa preparación do material, depende unha aula desenvolvida satisfactoriamente (de Miguel et al., 2005).

$\mathrm{Na}$ propia aula, durante o desenvolvemento da actividade é fundamental unha correcta explicación e definición das tarefas a desenvolver e problemas a solucionar. Para isto un enunciado correcto das preguntas de investigación semellan chave para conseguir uns bos resultados. Xa durante 0 desenvolvemento da actividade debe converterse en guía latente da actividade, atento a evitar un exceso de divagación e animando á explicitación de solucións ou conclusións e tratando de equilibrar os tempos se algún/ha estudante acapara en exceso as achegas ao grupo. É neste proceso cando ademais o profesor/a debe estar atento a rexistrar aqueles comentarios ou anotacións que lle poidan servir para avaliar posteriormente ao alumnado.

\subsubsection{ROL DO ALUMNADO NA METODOLOXÍA DO ESTUDO DO CASO}

0 alumnado chamado a desenvolver esta metodoloxía debe adoptar unha actitude activa na aula (en detrimento da da/o profesor/a). Deste xeito tras a exposición do caso obxecto de estudo, 0 alumnado

0 éxito desta técnica depende dunha boa disposición ou organización do alumnado. Así de Miguel et al. (2005) sinala que o número de alumnos/as debe situarse entre os 6 e os 10 . Deste xeito nun aula de 25-30 persoas poden crearse entre 3 e 5 grupos, dependendo do 
tamaño finalmente asignado. 0 traballo en grupos pequenos, aínda que despois se poida formar un grupo de aula ou grande grupo, é chave para conseguir unha maior participación dos individuos e de maior calidade, para promover 0 intercambio de ideas, para favorecer 0 debate, para lograr unha maior implicación individual -xa que a opinión de cada un/ha é relevante e interesante para chegar á conclusión do caso obxecto de estudo-, para conseguir unha retroalimentación por parte do resto de axentes do grupo e para acadar unha aprendizaxe de tipo activo, debido á implicación persoal de cada alumno/a.

\section{DEFINICIÓN DA PROPOSTA METODOLÓXICA}

\subsection{PLANIFICACIÓN DAS SESIÓNS}

0 profesorado que imparte esta materia entende que esta metodoloxía é a axeitada para desenvolver os seus contidos e competencias. Cada sesión de aula é de 3 horas de duración semanal. Dividiuse e axeitouse o contido do programa da materia a 12 sesións. Deste xeito defínese un caso distinto para cada unha das sesións.

0 contexto é empresarial-organizacional, xa que a materia así o permite. Para darlle unha maior verosimilitude e buscar unha maior motivación-activación por parte do alumnado optouse porque o/a axente ou relator/a de cada sesión fora un profesional das diferentes empresas do sector onde están chamados/as a desenvolver a súa práctica laboral. Así quen introduce e explica o caso é un/ha experto/a diferente. Á hora de contactar coas empresas pode aproveitarse aquelas que xa teñen relación co Mestrado e cos distintos graos de enxeñaría que se imparten na EUP de Ferrol para a realización das prácticas académicas. As/os distintas/os profesionais convidadas/os están desempeñando tanto postos intermedios como postos directivos no eido da economía da enerxía e da planificación financeira de empresas do sector (Figura 2). 


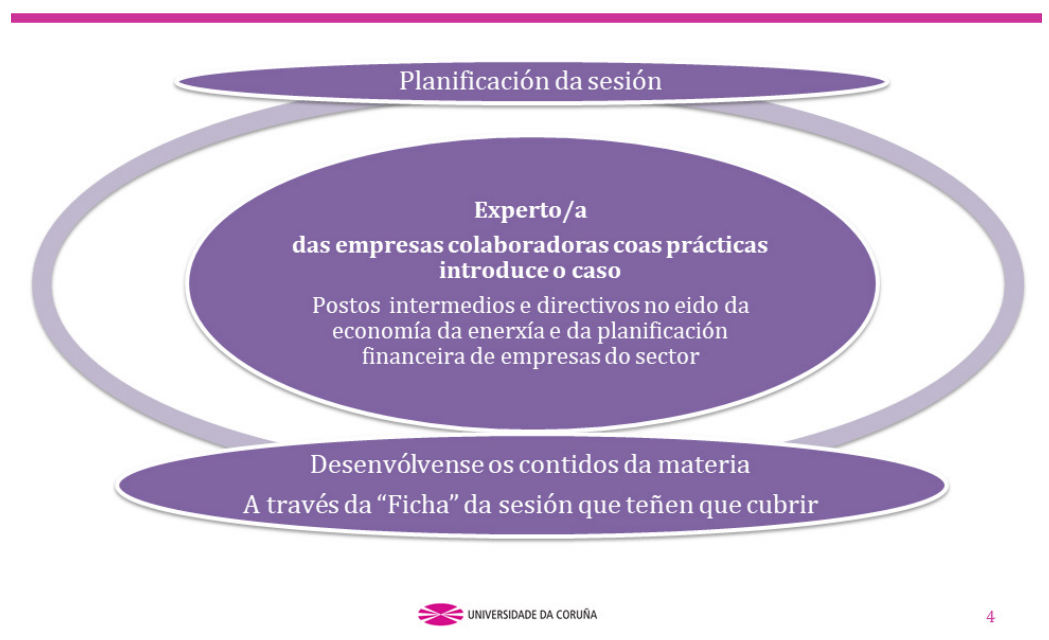

Figura 2. Desenvolvemento da proposta

A presenza desta/e experta/o na aula é recomendable e desexable, mais non obrigatoria. Deste xeito, en función da súa dispoñibilidade, o/a experto/a pode acompañar en persoa ao alumnado na aula, facer un skype ou enviar un vídeo onde explica o caso en cuestión. 0 caso definido inicialmente polo equipo de profesores é proposto á/o experta/o con anterioridade ao comezo do período lectivo. Con isto preténdese conseguir unha sinerxia entre 0 proceso creativo inicial do equipo de profesores da materia para cada caso enunciado e 0 equipo de profesionais expertos/as que colaboran na "dramatización" contextualizada. 0 enunciado do caso enriquécese así grazas á experiencia laboral do/a profesional asignado a cada caso. Aínda que nesta fase de creación o ideal sería manter tanto reunións nas que estean presentes todas/os e cada un/ha das/os profesionais convidados como reunións individuais con cada experta/0, a realidade conducirá en todo caso se é posible a ter unha primeira e unha última reunión previa coa totalidade (ou case) das/os expertas/os convidados e polo menos unha reunión individual dos/as docentes con cada un dos profesionais.

Segundo o exposto, a proposta académica baséase na creación dun enunciado "dramatizado" para cada un dos doce casos propostos así como na elaboración dunha ficha da sesión. Esta ficha é a que entrega a/o profesional relator do caso na sesión e que contén: 
- Un resumo da intervención da/o profesional

- As preguntas chave que guían o debate e a reflexión do grupo

- Unha serie de datos adicionais que poden servir para contextualizar

- Un apartado conclusivo no que se pide que o grupo expoña cal sería a súa solución á situación ou caso proposto.

Adicionalmente o profesorado ten preparada unha ficha solución na que se recolle unha posible resposta para cada unha das preguntas chave propostas para guiar 0 debate. Esta ficha solución entregarase nos momentos finais da sesión de aula para servir como contraste co traballado polos distintos grupos pequenos.

\subsection{DESENVOLVEMENTO DAS SESIÓNS}

Como se comentou, cada sesión comeza coa motivación e exposición do caso obxecto de estudo proposto pola/o profesional. Pode ser ben en persoa, ben cun skype ou un vídeo gravado previamente. A duración da exposición sitúase entre os 10 e os 15 minutos.

Unha vez presentado o caso a/o experta/o entrega a ficha correspondente á sesión que permite desenvolver os conceptos e traballalos ben en grande grupo de clase ou en pequenos grupos, dependendo do tema e dos conceptos a traballar.

Cada pequeno grupo, de ser o caso, sitúase na aula separado convenientemente do resto de pequenos grupos. A partir dese momento comeza 0 debate e a reflexión dos contidos a partir das preguntas chave propostas na ficha. A duración desta parte da dinámica está entre os 45 minutos e a hora e cuarto. Tras este tempo de reflexión e debate dáse un tempo de descanso de entorno a 10-15 minutos. Á volta do descanso dáselle un tempo de entorno a 15 minutos ou media hora a cada grupo para que conclúa as ideas solución ao caso proposto.

0 papel xa comentado do profesor da materia pasa de ser activo a latente, xa que este se converte nun "axente informativo" ao que acudir no caso de precisalo 0 alumnado (Figura 3). 0 debate e a reflexión entre iguais por parte do alumnado pasan a ser 0 elemento principal do desenvolvemento da aula. Deste xeito tanto o profesor como a/o experta/o están na aula e se 
achegan ao longo da sesión aos distintos grupos para poder resolver posibles dúbidas, axudar a resolver posibles problemas ou conflitos no grupo en relación coas intervencións, o reparto de tarefas dentro do mesmo ou cos tempos empregados. Ambos axentes deben estar atentos ao desenvolvemento levado a cabo por cada grupo e conseguir que ningún deles quede descolgado do ritmo básico de cumprimento da tarefa.

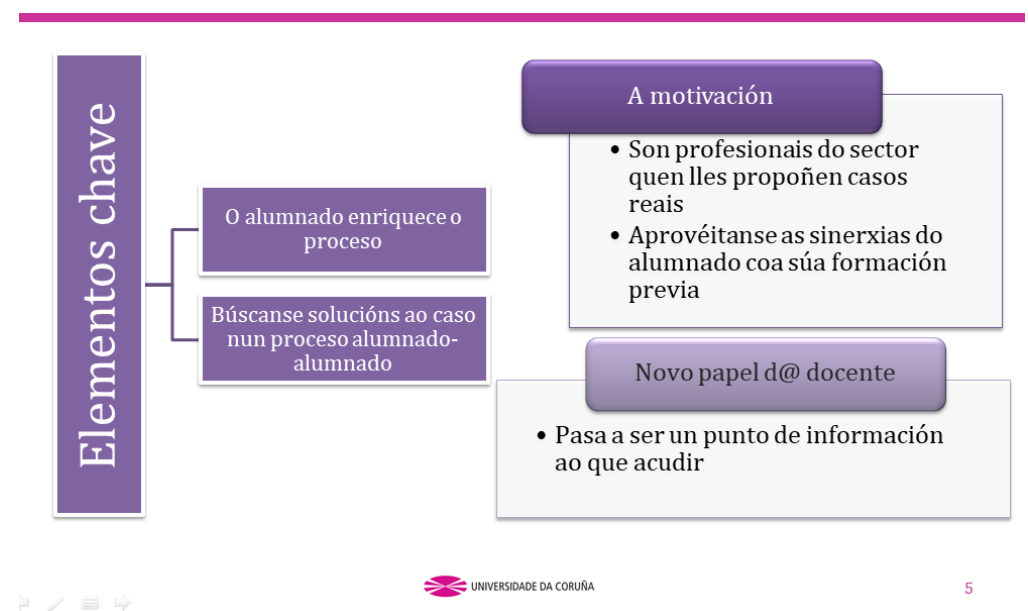

Figura 3. Desenvolvemento da proposta

Nos últimos 45-50 minutos da sesión volve intervir a/o profesional relator convidada/o para animar a poñer en común as conclusións de cada pequeno grupo. Unha vez expostas e comentadas as conclusións dos grupos entrégase ou visualízase co proxector as ideas contidas na ficha solución para xerar un último momento de debate e reflexión entre todos os axentes (alumnado, docente, experta/a) para concluír o caso traballado.

\section{CONCLUSIÓNS}

Mediante esta reformulación da materia conséguese que sexa o propio alumnado quen asume o papel principal do proceso de ensinanza-aprendizaxe e 0 enriquece. 0 contexto búscase que sexa de motivación a partir da participación de profesionais do futuro sector laboral. Así 
mesmo, preténdese dar solución aos problemas propostos -en forma de casos- a partir das sinerxias derivadas da experiencia formativa previa do alumnado.

\section{REFERENCIAS}

Alonso, A.M. (2008). Acerca del nuevo modelo de formación del profesorado. En Ávila, R.M, Alcázar C. \& Díez, M.C. (Eds.). Didáctica de las Ciencias Sociales, Currículo Escolar y Formación del Profesorado. La didáctica de las Ciencias Sociales en los nuevos planes de estudios (pp. 157-168.). Jaén (España): Universidad de Jaén.

Bará, M. \& Domingo, J. (2005). "Técnicas de aprendizaje cooperativo. Taller de Formación. Universitat Politécnica de Catalunya". Recuperado de: http://www.catedu.es/doc_intercultural/recursos/pdfs/TecnicasAprendizajecooperativo. pdf.

Bozu, Z. (2008). La carpeta docente como práctica formativa y de desarrollo profesional del profesorado universitario novel. Un estudio de casos. Barcelona (España): Universitat de Barcelona.

Cano, R. (2009). Tutoría universitaria y aprendizaje por competencias ¿Cómo lograrlo?. Revista Electrónica Interuniversitaria de Formación del Profesorado, 12 (1), pp. 181204. Recuperado de: http://www.aufop.com/

De Miguel, M. (Dir); Alfaro, I.J., Apodaca, P., Arias, J.M.; García, E.; Lobato, C. \& Pérez, A. (2005). Modalidades de enseñanza centradas en el desarrollo de competencias. Orientaciones para promover el cambio metodológico en el Espacio Europeo de Educación Superior. Oviedo (España): Universidad de Oviedo.

Fernández, M. \& De-Llano, F. (2013). El Plan de Acción Tutorial en la Universidad: Seguimiento del PAT de la Facultad de Economía y Empresa de la UDC y su función como plataforma educativa integral dentro del EEES. Taller Docente de la XV Reunión de Economía Mundial (REM). La riqueza cambiante en la Economía Mundial, Santander. Recuperado de: https://dialnet.unirioja.es/servlet/articulo? codigo $=4268883$. 
Gutierrez, P. \& Castro, M.P. (2018). El aprendizaje entre iguales como metodología de trabajo para la inclusión educativa. Experiencia docente en una escuela de Extremadura. Revista de Investigación en Educación, 1 (16), pp. 78-92.

Riesco, M. (2008). El enfoque por competencias en el EEES y sus implicaciones en la enseñanza y el aprendizaje. Tendencias Pedagógicas, 13, pp. 79-105.

Robledo, P., Fidalgo, R., Arias, O., Álvarez, M.L. (2015). Percepción de los estudiantes sobre el desarrollo de competencias a través de diferentes metodologías activas. Revista de Investigación Educativa, 33(2), 369-383. 